\title{
Multiple electrode aggregometry as a method for platelet function assessment according to the European guidelines
}

\author{
Jan Pluta, Barbara Nicińska, Janusz Trzebicki
}

\author{
I Department of Anaesthesiology and Intensive Therapy, Medical University of Warsaw, Poland
}

\begin{abstract}
Platelets play an essential role in haemostasis. Assessment of their function is vital for anaesthesiologists evaluating haemostatic potential, especially during emergency operations. The monitoring of platelets function had been implemented into the European recommendations for management of perioperative and posttraumatic bleeding. One of the diagnostic methods described in the recommendations is multiple electrode aggregometry. As antiplatelet therapy becomes more widely used in modern medicine, this method, in contrast to standard laboratory tests, can significantly help to identify patients with drug-induced thrombocytopaty. The aggregometry enables prompt evaluation of the platelets aggregation which is very useful for everyday decision-making in goal-directed hemostatic therapy.
\end{abstract}

Anaesthesiology Intensive Therapy 2018, vol. 50, no 3, 230-233

Key words: haemostasis, platelets, bleeding, thrombocytopathy, multiple electrode aggregometry

Blood platelets (PLT) are a basic morphotic element of haemostasis. The platelet count determined in peripheral blood testing is routinely taken into consideration while assessing the safety of surgical procedures, including anaesthesia (e.g. central and peripheral nerve blocks, vessel cannulation). Since antiplatelet drugs are commonly used, quantification of thrombocytes may not be sufficient to stratify the patient's perioperative risk of bleeding.

To obtain the most reliable information regarding the haemostatic potential of PLT, it is vital to assess them qualitatively. The process of platelet haemostasis occurs in three stages: platelet activation, adhesion and aggregation. Some specific disturbances can occur during each of these stages, preventing the formation of a cohesive, permanent platelet plug.

The first reports concerning the methods of PLT function assessment were published more than one hundred years ago. The bleeding time introduced into clinical practice by Duke was used to assess the time needed to form a platelet plug after mechanical disruption of tissue continuity. For many years, further advances in diagnostic procedures associated with this issue were hindered by difficulties in PLT activation in vitro. A breakthrough was light transmission aggregometry (LTA), in which aggregation results from the use of appropriate agonists of PLT receptors (adenosine, arachidonic acid, adrenaline, collagen) [1, 2]. As the platelet plug grows, a proportional increase in the intensity of a visible light beam passing through the sample is recorded. Despite its faults (platelet-rich plasma or specialist laboratory facilities that are needed), LTA is still regarded as the gold standard of PLT function testing [3].

In recent years, the methods assessing the function of PLT have been substantially developed and popularised, which is associated with the availability of easier-to-operate and automated devices, no need for earlier preparation of samples (whole blood assessment) and the fact that the results can be obtained within several minutes. The technological advances have contributed to the development of point-of-care (POC) tests for PLT function assessment [4, 5].

The POC methods for assessment of thrombocytes are based on the analysis of aggregation and adhesion of PLT, evaluation of the effects of shear forces on the formation of a platelet plug, flow cytometry and the presence of thromboxane metabolites [6].

The POC test, which assesses the process of aggregation in a similar way as LTA, is multiple electrode aggregometry (MEA). MEA is a comprehensive diagnostic method for the assessment of PLT dysfunctions [7]. The undoubted assets of MEA, as compared with LTA, are a substantial simplification of the diagnostic process (no need to use platelet-rich 
plasma), a shorter time required for obtaining results (less than 10 minutes) and no need for qualified laboratory diagnosticians to operate the equipment. Therefore, MEA is used for quick diagnosis of haemostatic disturbances.

The device using MEA for platelet function assessment is a Multiplate analyser (Roche, Switzerland) (Fig. 1). The technique is based on the evaluation of changes in electrical impedance observed between the two double metal electrodes immersed in blood. Whole blood samples are collected in test tubes with hirudin or citrate. Once the agonist of a particular pathway of activation is added to the sample, the impedance increases proportionally, which is associated with progressive aggregation of PLT on the electrodes. The process is recorded graphically. To increase accuracy, the measurement is recorded simultaneously from two electrodes (two curves in the figure). The result (area under the curve) is also expressed as a numerical value, which can be related to the reference values calculated for each test (Fig. 2).

The assessment involves the pathways of PLT aggregation dependent on cycloxygenase (ASPItest), collagen (COLtest), adenosine diphosphate (ADPtest), thrombin (TRAPtest) and von Willebrand factor (RISTOtest) [8].

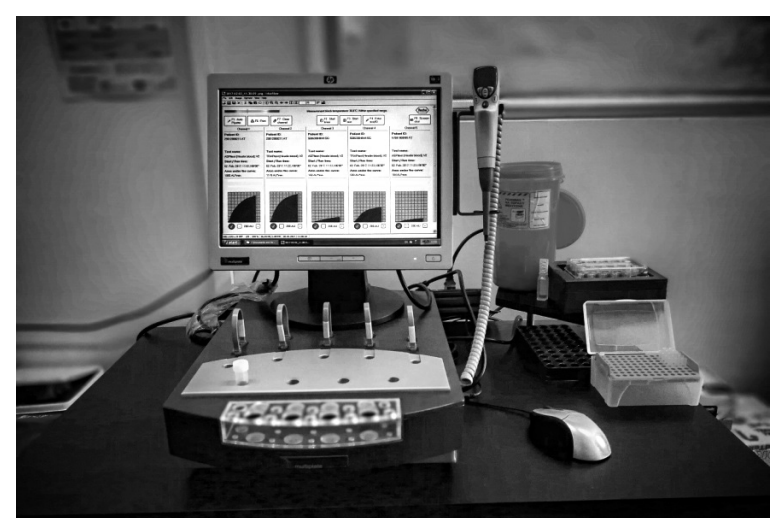

Figure 1. The Multiplate analyser (authors` material)
The Multiplate device can be used for determinations of PLT functions in patients on antiplatelet drugs (Fig. 3). MEA enables monitoring of the changes in PLT aggregation induced by acetylsalicylic acid and nonsteroidal anti-inflammatory drugs (ASPItest), derivatives of thienopyridine - ticlopidine, clopidogrel, prasugrel, ticagrelor (ADPtest) or GPIlb/Illa receptor blockers - abciximab, tirofiban or eptifibatide (TRAPtest) $[5,9]$.

The limitations of MEA include the necessity to consider the effects of haematocrit and platelet count (especially thrombocytopenia) on the result obtained [7] and no possibility to evaluate the impact of vascular endothelium and shear forces during the blood flow through the vessels due to in vitro nature of the test.

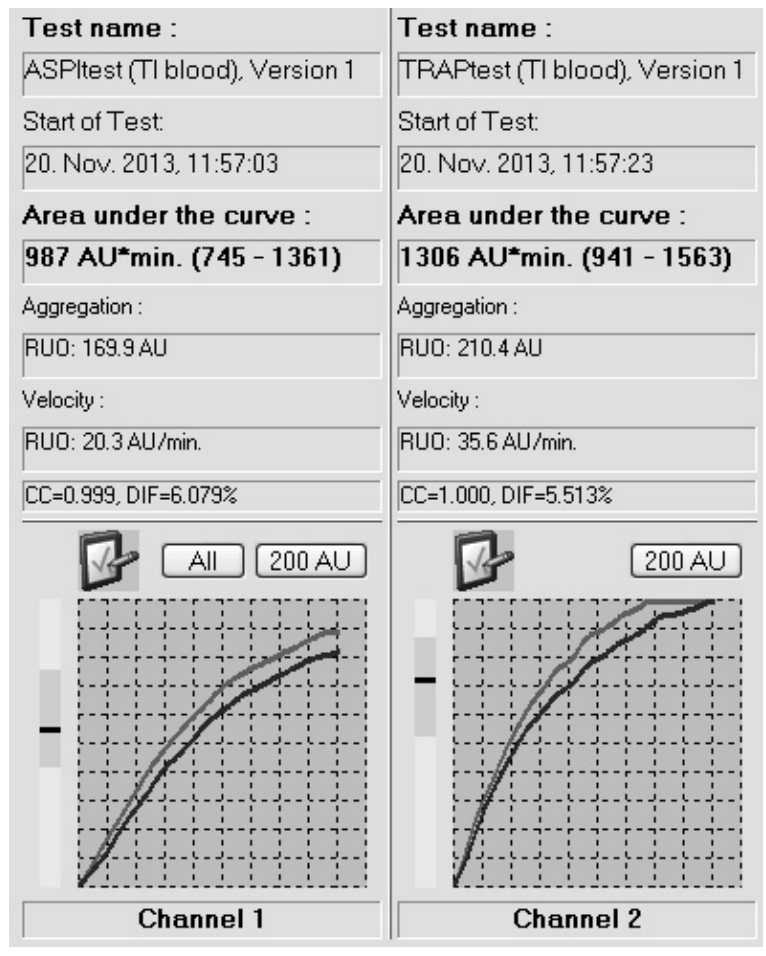

Figure 2. A graphic representation of the example MEA result using the Multiplate analyser (authors` material)

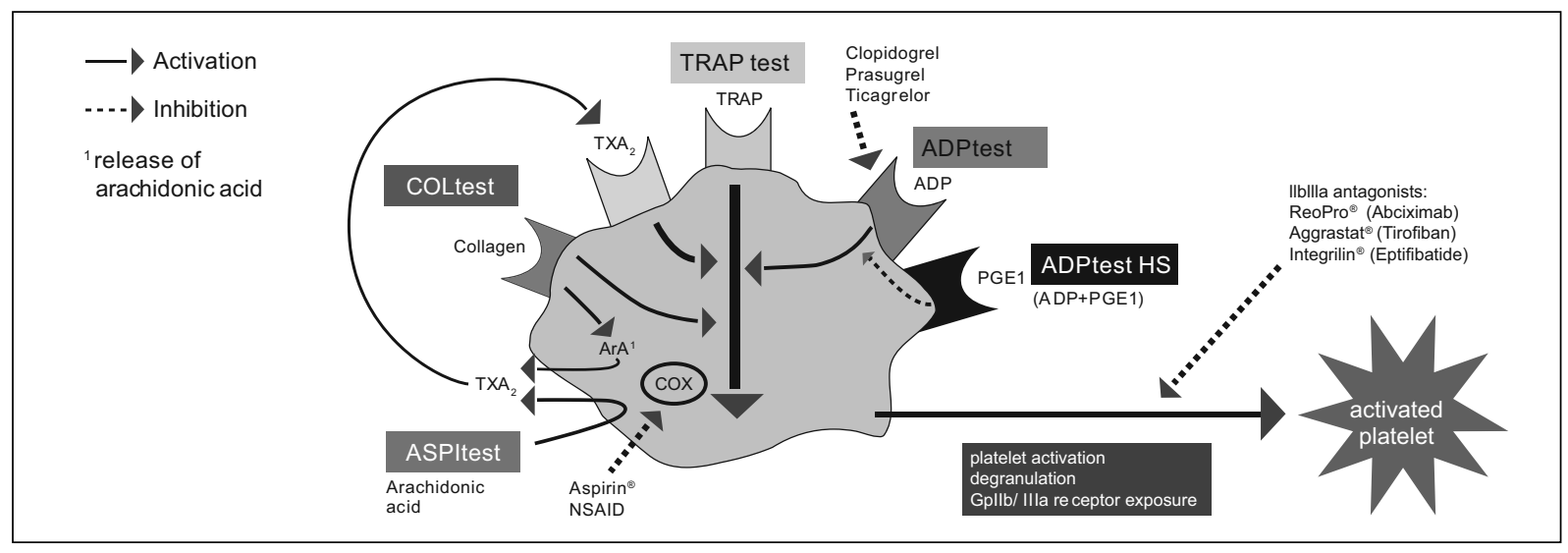

Figure 3. Points of action of antiplatelet drugs (source: courtesy of Roche Diagnostics Polska) 
POC devices are increasingly being used in operating suites, intensive care units, emergency departments, intensive cardiologic care units or cardiac surgery departments. Thanks to them, patients with congenital and acquired (e.g. post-drug) PLT disturbances can be identified, the perioperative risk of bleeding stratified and blood preparations provided, if need be. Moreover, the efficacy of antiplatelet therapy can be monitored to increase the safety of central and peripheral blocks [7].

The new methods for PLT function assessment provide relevant information about the haemostasis system; therefore, their use was recommended in the guidelines of the European Society of Anaesthesiology for management of massive bleedings [10] and major trauma-related bleedings [11].

Platelet dysfunctions are one of the causes of posttrauma coagulopathy. The guidelines mentioned above emphasise the shortage of studies evaluating PLT function in trauma patients. The authors stress that in cases of major traumas, the evaluation of primary haemostasis based solely on the PLT count can lead to ineffective haemostatic therapy $[12,13]$. Due to the lack of PLT function assessment in patients with post-trauma coagulopathy whose PLT count is within the reference values, PLT concentrate transfusions can be abandoned, which is likely to increase the mortality. Solomon et al. [14] have discovered that in a group of patients who died due to their injuries, the MEA results were below the reference values at the normal PLT count. The same correlation was observed by Jacoby et al. [15] in patients with traumatic brain injury. The recommended management for the diagnosis of massive bleedings is a combined use of the methods for PLT function assessment and the global tests for haemostasis, such as thromboelastometry (ROTEM) or thromboelastography (TEG) [16], as ROTEM and TEG show poor sensitivity for detecting and monitoring PLT dysfunction resulting from the effects of antiplatelet drugs and some other factors [14]. The European guidelines recommend the use of multiple electrode aggregometry in patients with massive bleedings and posttrauma coagulopathy suspected of using drugs blocking platelet function (a grade 2 recommendation) [11].

Moreover, perioperative monitoring of haemostasis assessing PLT function provides relevant therapeutic information for cardiac surgery in which their dysfunction is a significant cause of bleedings [17, 18]. The preoperative use of MEA (ADPtest) amongst patients receiving thienopyridine derivatives and undergoing surgical procedures with extracorporeal circulation enables the identification of patients at high risk of postoperative bleeding [19]. The combined use of MEA and global haemostasis tests (ROTEM or TEG) contributed to reduced costs and improved treatment outcomes in cardiac surgery [20].
The methods assessing PLT function are also used in transplant surgery as increased PLT aggregation in the ADPtest has been demonstrated to be positively correlated with ischaemic postreperfusion liver injury, impaired early graft function and thrombocytopenia [21].

An important issue included in the European guidelines is the common use of antiplatelet drugs amongst patients undergoing anaesthetic and surgical procedures. The authors of recommendations emphasise the lack of explicit guidelines regarding the intervals between antiplatelet drug discontinuation and the intervention to be performed [10]. Bergmann et al. [22] used the ADPtest for the evaluation of platelet blockage in a patient receiving ASA and clopidogrel chronically, whose earlier-inserted epidural catheter had to be removed. A certain limitation is the lack of defined reference values that could be used to determine the restoration of complete PLT function in cases where antiplatelet therapy has been discontinued. MEA performed before the initiation of antiplatelet therapy can prove useful for determination of an individual level of PLT aggregation. Subsequently, this result can be considered a reference point for PLT function restoration in a particular patient (Fig. 4). The European recommendations stress the importance of a short time needed for POC testing, which enables multiple measurements and an evaluation of the dynamic nature of the ongoing changes. The factor which can affect the reliability of MEA results is the presence of thrombocytopenia. The

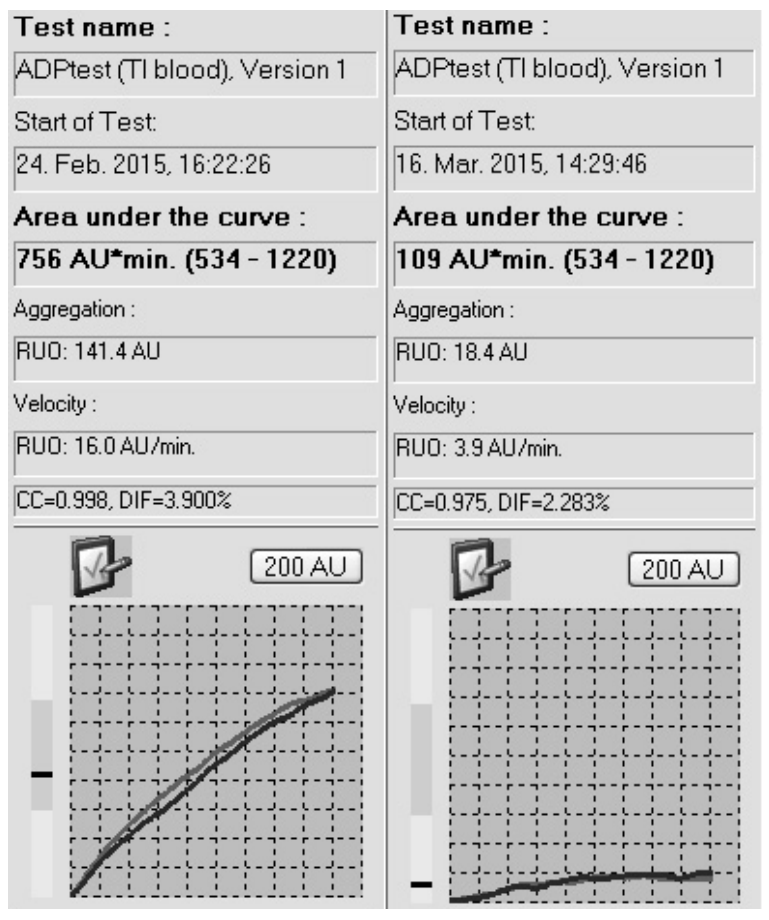

Figure 4. The baseline test before the procedure and use of clopidogrel (left) and 14 days after antiplatelet therapy (right) (authors` material) 
optimal PLT count is considered to be above $100 \mathrm{G} \mathrm{L}^{-1}$ [23]. The use of MEA can also prove useful for monitoring the effects of the therapeutic intervention applied, such as the administration of desmopressin or platelet concentrate transfusion [24, 25]. It is emphasised that in antiplateletnaive patients, the TRAPtest is the MEA option reflecting the "global" PLT aggregative potential [19].

\section{SUMMARY}

According to the European guidelines, PLT function assessment using multiple electrode aggregometry is an important tool supporting the stratification of the risk of haemostatic disturbances in the perioperative period and after trauma. The method used in patients on antiplatelet drugs, or in those with active bleedings following multiple organ injuries, provides clinically relevant information that can reduce the risk of haemorrhagic and thromboembolic complications. Moreover, the use of MEA in everyday practice may be one of the elements of diagnostic management increasing the safety of surgical procedures, including anaesthetic management.

\section{ACKNOWLEDGEMENTS}

1. Source of funding: none.

2. Conflict of interest: none.

\section{References:}

1. Born GV. Aggregation of blood platelets by adenosine diphosphate and its reversal. Nature. 1962; 194: 927-929, indexed in Pubmed: 13871375.

2. Born G, Cross MJ. The aggregation of blood platelets. J Physiol . 1963; 168(1): 178-195, doi: 10.1113/jphysiol.1963.sp007185.

3. Syska K, Kosiorek A, Podsędek A, et al. Propozycja procedury oceny przeciwpłytkowych właściwości preparatów polifenolowych pochodzenia roślinnego $w$ badaniach in vitro. Postępy Fitoter. $2012 ; 1: 3-10$.

4. Görlinger $K$, Jambor $C$, Dirkmann $D$, et al. Platelet function analysis with point-of-care methods. Herz. 2008; 33(4): 297-305, doi: 10.1007/ s00059-008-3130-4, indexed in Pubmed: 18581079.

5. Jámbor C, Weber CF, Gerhardt K, et al. Whole blood multiple electrode aggregometry is a reliable point-of-care test of aspirin-induced platelet dysfunction. Anesth Analg. 2009; 109(1): 25-31, doi: 10.1213/ ane.0b013e3181a27d10, indexed in Pubmed: 19439684.

6. Pakala R, Waksman R. Currently available methods for platelet function analysis: advantages and disadvantages. Cardiovasc Revasc Med. 2011; 12(5): 312-322, doi: 10.1016/j.carrev.2010.09.005, indexed in Pubmed: 21036109

7. Paniccia R, Priora R, Liotta AA, et al. Platelet function tests: a comparative review. Vasc Health Risk Manag. 2015; 11: 133-148, doi: 10.2147/VHRM. S44469, indexed in Pubmed: 25733843.

8. Vidali $M$, Rolla R, Parrella $M$, et al. Role of the laboratory in monitoring patients receiving dual antiplatelet therapy. Int J Lab Hematol. 2012; 34(5): 484-494, doi: 10.1111/j.1751-553X.2012.01428.x, indexed in Pubmed: 22613071

9. Paniccia R, Antonucci E, Maggini N, et al. Assessment of platelet function on whole blood by multiple electrode aggregometry in high-risk patients with coronary artery disease receiving antiplatelet therapy. Am J Clin Pathol. 2009; 131(6): 834-842, doi: 10.1309/AJCPTE3K1SGAPOIZ, indexed in Pubmed: 19461090

10. Kozek-Langenecker SA, Ahmed AB, Afshari A, et al. Management of severe perioperative bleeding: guidelines from the European Society of Anaesthesiology. Eur J Anaesthesiol. 2013;30(6): 270-382, doi: 10.1097/ EJA.0b013e32835f4d5b, indexed in Pubmed: 23656742.

11. Rossaint R, Bouillon B, Cerny V, et al. Task force for advanced bleeding care in trauma. Management of bleeding following major trauma: an updated European guideline. Crit Care. 2010; 14(2): R52, doi: 10.1186/ cc8943, indexed in Pubmed: 20370902

12. Kutcher ME, Redick BJ, McCreery RC, et al. Characterization of platelet dysfunction after trauma. JTrauma Acute Care Surg. 2012; 73(1): 13-19, doi: 10.1097/TA.0b013e318256deab, indexed in Pubmed: 22743367.

13. Brown LM, Call MS, Margaret Knudson M, et al. Trauma outcomes group. A normal platelet count may not be enough: the impact of admission platelet count on mortality and transfusion in severely injured trauma patients. J Trauma. 2011; 71(2 Suppl 3): S337-S342, doi: 10.1097/ TA.0b013e318227f67c, indexed in Pubmed: 21814101.

14. Solomon C, Traintinger S, Ziegler B, et al. Platelet function following trauma. A multiple electrode aggregometry study. Thromb Haemost. 2011; 106(2): 322-330, doi: 10.1160/TH11-03-0175, indexed in Pubmed: 21655681.

15. Jacoby RC, Owings JT, Holmes J, et al. Platelet activation and function after trauma. J Trauma. 2001; 51(4): 639-647, indexed in Pubmed: 11586152.

16. Rossaint R, Bouillon B, Cerny V, et al. The European guideline on management of major bleeding and coagulopathy following trauma: fourth edition. Crit Care. 2016; 20: 100, doi: 10.1186/s13054-016-1265-x, indexed in Pubmed: 27072503.

17. Hartmann M, Sucker C, Boehm O, et al. Effects of cardiac surgery on hemostasis. Transfus Med Rev. 2006; 20(3): 230-241, doi: 10.1016/j. tmrv.2006.03.003, indexed in Pubmed: 16787830.

18. Solomon C, Hartmann J, Osthaus A, et al. Platelet concentrates transfusion in cardiac surgery in relation to preoperative point-of-care assessment of platelet adhesion and aggregation. Platelets. 2010; 21(3): 221-228, doi: 10.3109/09537100903560155, indexed in Pubmed: 20158381.

19. Ranucci M, Baryshnikova E, Soro G, et al. Surgical and Clinical Outcome Research (SCORE) Group. Multiple electrode whole-blood aggregometry and bleeding in cardiac surgery patients receiving thienopyridines. Ann Thorac Surg. 2011; 91(1): 123-129, doi: 10.1016/j. athoracsur.2010.09.022, indexed in Pubmed: 21172499.

20. Weber CF, Görlinger K, Meininger D, et al. Point-of-care testing: a prospective, randomized clinical trial of efficacy in coagulopathic cardiac surgery patients. Anesthesiology. 2012; 117(3): 531-547, doi: 10.1097/ ALN.0b013e318264c644, indexed in Pubmed: 22914710.

21. Schulte am Esch J, Akyildiz A, Tustas RY, et al. ADP-dependent platelet function prior to and in the early course of pediatric liver transplantation and persisting thrombocytopenia are positively correlated with ischemia/reperfusion injury. Transpl Int. 2010; 23(7): 745-752, doi: 10.1111/j.1432-2277.2010.01054.x, indexed in Pubmed: 20136783.

22. Bergmann L, Kienbaum P, Görlinger K, et al. Uneventful removal of an epidural catheter guided by impedance aggregometry in a patient with recent coronary stenting and treated with clopidogrel and acetylsalicylic acid. Reg Anesth Pain Med. 2007; 32(4): 354-357, doi: 10.1016/j. rapm.2007.06.007, indexed in Pubmed: 17720122.

23. Hanke $A A$, Roberg $K$, Monaca $E$, et al. Impact of platelet count on results obtained from multiple electrode platelet aggregometry (Multiplate). Eur J Med Res. 2010; 15(5): 214-219, indexed in Pubmed: 20562061.

24. Rahe-Meyer N, Winterhalter M, Boden A, et al. Platelet concentrates transfusion in cardiac surgery and platelet function assessment by multiple electrode aggregometry. Acta Anaesthesiol Scand. 2009; 53(2): 168-175, doi: 10.1111/j.1399-6576.2008.01845.x, indexed in Pubmed: 19175576.

25. Weber CF, Dietrich W, Spannagl M, et al. A point-of-care assessment of the effects of desmopressin on impaired platelet function using multiple electrode whole-blood aggregometry in patients after cardiac surgery. Anesth Analg. 2010; 110(3): 702-707, doi: 10.1213/ ANE.0b013e3181c92a5c, indexed in Pubmed: 20042444.

\section{Corresponding author:}

Jan Pluta

I Department of Anaesthesiology

and Intensive Care, Medical University of Warsaw

ul. Lindleya 4, 02-005 Warszawa, Poland

e-mail:jan.pluta@lekarz.eu

Received: 1.04.2017

Accepted: 30.04 .2018 